\title{
Recordatorio de Ricardo Jaimes Freyre
}

\author{
"lírico potente, delicado, sabio en \\ técnica y elevado en numen." \\ (Rubén Darío, Autobiografía, \\ Ed. Mundo Latino, p. 148.)
}

MURIO hace diez años. En vida, allá por los muy últimos días res del movimiento modernista. Entre los escritores que quisieron liberarse de las vías trilladas de la poética romántica y academizada, por aquel entonces, él fué quizás el más consciente de los artesanos y el más programáticamente articulado de los poetas. Fuera o no adecuada, él tuvo y mantuvo una teoría del verso y de la poesía y a ella permaneció adicto en su obra estética.

Precisamente por su tendencia disciplinante en un movimiento sin disciplina lleno de íntimas contradicciones, la poesía de Ricardo Jaimes Freyre va siendo olvidada y sus poemas relegados a un rincón de las antologías. Sus versos esperan todavía una edición opera omnia; algunos están esperando aún la primera edición.

Ricardo Jaimes Freyre nació en la vieja ciudad del cerro argentífero, Potosí, en Bolivia. Artículos, estudios y antologías están en desacuerdo en cuanto a la fecha de su nacimiento: 1868, 1870, 1872, 1873. Hasta obtener la fecha auténtica baste indicar que debió ser ligeramente más joven que Darío (1867) y que emparejaba, en cuanto a la edad, con la generación de los Nervo, los Valencia, Lugones, Herrera y Reissig, Chocano, nacidos todos entre 1870 y 1873. Su tránsito ocurrió en Buenos Aires el día 24 de abril de 1933. 
Perteneció Ricardo Jaimes Freyre a una familia distinguida en la vida política y en la vida artística de su país.

Su padre, Julio Lucas Jaimes, también natural de Potosí, habíase dedicado desde muy joven a la literatura y a la política. Sus poesías son por lo general jocosas y familiares y le parecían a don José Domingo Cortés originales y chistosas. Por los años de 1868 publicó en La Revista del Sur, en Tacna, las primeras de sus tradiciones bolivianas, por el estilo de las de Palma, reunidas más tarde en su mejor obra: La villa imperial de Potosí. Su historia anecdótica. Sus tradiciones y leyendas fantásticas. Su grandeza y su opulencia fabulosas (Buenos Aires, Ed. Rosso, 1905). Fué regidor de su ciudad natal, profesor de literatura y filosofía, militar en la guerra con Chile, director general de Estadística, diputado, crítico literario, redactor de varios periódicos, panfletario político, etc. Enviado a Río de Janeiro como Encargado de Negocios de Bolivia, no alcanzó a llegar al Brasil, deteniéndose en Buenos Aires, donde se estableció ya para siempre profesando filosofía en el Colegio Nacional y estética en la Normal de Maestras y colaborando asiduamente en La Nación, bajo el seudónimo de "Brocha Gorda". Escribió también varias obras teatrales y una novela de costumbres bonaerenses.

Este personaje de actividades proteicas estaba casado con doña Carolina Freyre, natural de Tacna, en cuyo Colegio Nacional de Educandas había realizado sus estudios y sido, a muy tierna edad, profesora de la clase de matemáticas. Allí mismo, en la revista La Bella Tacneña y luego en La América y otros periódicos de Lima, publicó esta dama sus primeras poesías, de las que pueden verse algunas en publicaciones antológicas de la época que se indican en la lista de trabajos consultados.

De tal matrimonio nacieron hijos favorecidos por las Musas. E1 hermano menor de Ricardo Jaimes Freyre, Raúl, nacido en 1886, se ha distinguido en Bolivia como profesor de Bellas Artes, escritor, pintor y músico. Es autor de varios libros, en verso y en prosa: Los paisajes lejanos. Pequeñas canciones de la ciudad y del campo. Voces Lel claustro. Tierras de Potosí. Otras Canciones, Potosí, 1907; Los desheredados, La Paz, 1933; Evangelio infantil, La Paz, 1933; Potosi, La Paz, 1933; Al final del viaje (Premio de la Academia de Italia), La Paz, 1935. Ha sido hombre de vida atormentada entre cl amor y el misticismo, llegando a encerrarse por una temporada en una institución religiosa de La Paz. Sus obras pictóricas han al- 
canzado varias veces premios y medallas en las exposiciones paceñas, y sus obras poéticas, numerosas recompensas en certámenes y juegos florales.

La personalidad de Ricardo Jaimes Freyre encontró, por lo tanto, ambiente familiar propicio y comprensivo al desarrollo de sus actividades literarias, cosa normal en el marco de su casa.

La biografía de nuestro poeta aparece vaga, y más que vaga confusa, en las noticias impresas que existen. Según una, Ricardo Jaimes Freyre se educó en Buenos Aires ; según otra, su educación hízose en un colegio preparatorio de Lima y luego en la Universidad de San Francisco Javier de Chuquisaca, en la que obtuvo el doctorado en Derecho y Jurisprudencia y en la que se le confió, inmediatamente después de su graduación, la enseñanza de Historia y Literatura. Por fin, según una tercera noticia, a los veintiún años fué nombrado profesor de Filosofía en la Escuela Junín de Sucre.

Sea de ello lo que fuere, su biografía se precisa desde que comienza a actuar en la vida política de su país, a la que le llamaba la situación familiar.

El Presidente de Bolivia, Mariano Bautista (1892-1896), le nombró su secretario particular. Durante su servicio en la Presidencia, contrajo matrimonio con doña Felicidad Soruco y de él se nos dice que fué siempre "hombre de intensa y profunda ternura familiar". Al poco tiempo fué nombrado secretario de la Legación de Bolivia en Buenos Aires, de la que pasó a la de Río de Janeiro. Encontrándose de Encargado de Negocios en esta última capital, estalló en La Paz la revolución de 1898, dirigida por el coronel Pando contra el Presidente doctor Severo Alonso, so pretexto de protestar contra el decreto que hacía de Sucre la capital permanente de la República, en oposición a la costumbre de la rotación de la capitalidad. Ricardo Jaimes Freyre dimitió su cargo y marchó a Buenos Aires con ánimo de dedicarse allí al periodismo.

Esta fué la época de su amistad con Rubén Darío y con él fundó en la capital argentina La Revista de América, que fué, durante su corta vida, portaestandarte de las doctrinas del modernismo literario. A tal aventura editorial se refiere Rubén Darío en su Autobiografía, páginas 147 y 148 , en las que menciona con cariño y con respeto a Julio Lucas Jaimes y a Ricardo Jaimes Freyre, diciendo de este último las palabras que encabezan el presente artículo. 
En 1899 imprimió Jaimes Freyre en La Paz un drama, La hija de Jephté, y el mismo año publicó en Buenos Aires su libro de versos Castalia bárbara, prologado por Leopoldo Lugones, que constituye, después de Prosas profanas (1896) y de Las montañas del oro (1897), uno de los libros de poesía más importantes del movimiento modernista.

Por entonces fué llamado Ricardo Jaimes Freyre a la ciudad de Tucumán, donde residió hasta su reincorporación, en 1920, a la vida pública boliviana.

Los años de residencia en Tucumán fueron laboriosos para nuestro escritor: catedrático de Literatura y de Filosofía del Colegio Nacional, cofundador y profesor de la Universidad, Presidente del Departamento de Educación, historiador de la provincia, inspirador de la Revista de Letras y Ciencias Sociales y, en general, centro de un grupo motor de actividad intelectual en la provinciana población.

Durante estos años publicó su obra teórica sobre métrica, primero en artículos en la revista citada (1906) y luego en su libro Leyes de la versificación castellana (1912); escribió también obras históricas sobre el Tucumán colonial, que requirieron viajes al Archivo de Indias de Sevilla, al de Simancas y a otros de Hispanoamérica y de Europa; en 1917 publicó su libro de versos Los sueños son vida y en 1918 una segunda edición de Castalia bárbara. A instancias de su anigo Alberto Rougés terminó un drama histórico, Los conquistadores, impreso más tarde en La $\mathrm{Paz}$ (1928); y, según nos dice su colega el rector de la Universidad de Tucumán don Juan B. Terán (en Nosotros, Buenos Aires, de abril de 1933), escribió también otro libro de versos, El taller de Eufranor, que permanece inédito.

En julio de 1920 se sublevó Bolivia contra el Presidente Guerra; Ricardo Jaimes Freyre volvió a su patria, fué elegido miembro de la Convención y alcanzó las carteras de Instrucción Pública primero y de Relaciones Exteriores después, bajo la administración del Presidente Bautista Saavedra. Estuvo en misión diplomática especial en la Argentina, en el Uruguay y en el Brasil y luego se le confió el delicado encargo de negociar con Chile la revisión del tratado de 1904, que había consagrado en condiciones por demás onerosas para Bolivia su privación de todo acceso territorial al Pacífico. En 1923 fué enviado a Washington como Ministro Plenipotenciario y 
más tarde, con la misma categoría, a Río de Janeiro, cargo éste que dimitió por un choque con su Gobierno, pasando a residir privadamente en Buenos Aires. En la capital argentina vivió en modestísima situación económica, hasta su fallecimiento.

Tres retratos hemos visto de Ricardo Jaimes Freyre, uno en el Bulletin of the Pan American Union, de diciembre de 1923; otro en Nosotros, de abril de 1933, y el tercero en Repertorio Americano, de San José de Costa Rica, de 12 de agosto de 1933. En esta última revista y fecha, figura un artículo del escritor boliviano Fernando Díez de Medina en el que nos da la siguiente descripción del aspecto físico y moral de Ricardo Jaimes Freyre:

Mediana la estatura. Erguido el torso varonil.' Alta la frente. Señorial el porte. De rasgos firmes y duro el rostro; apretada la piel; cruzados de vivacidad y altaneros los ojos. Decorando la imponencia del rostro, el escorzo atrevido de los mostachos mosqueteriles. Y luego el clásico chambergo alado voluntariosamente sobre la rebelde y crinada melena. Solemne el gesto, la voz sonora y grave, fluían las palabras con majestad...

Político o diplomático, maestro, poeta u hombre de mundo, estará siempre erguido en su natural distinción, revestido de aquella fría y segura serenidad que le permitió afrontar desdeñosamente situaciones y obstáculos.

Antes de entrar al examen de la poesía de Ricardo Jaimes Freyre, conviene fijar la cronología de su producción, intentada en 1a siguiente forma :

Castalia Bárbara. Prólogo de Leopoldo Lugones. 1 a edición. Buenos Aires, 1899.

Castalia bárbara. Pais de sueño. País de sombra. 2ạ edición. La Paz, Editorial Los Andes (González y Medina), 1918.

Castalia bátbara. Los sueños son vida. Madrid, Editorial América, Biblioteca Andrés Bello, LII, (1918).

Castalia bátbara y otros poemas. (Castalia bátbata, País de sueño, País de sombra, Los sueños son vida, Anadiomena, Las víctimas.) (México), Ed. Cultura, 1920.

La hija de Jephté. Drama en dos actos en prosa. La Paz, Tipografía El Siglo Industrial, 1899.

Historia de la República de Tucumán. Buenos Aires, Coni Hnos., 1911. 
Leyes de la versificación castellana. 1a edición. Buenos Aires, Coni Hnos, 1912.

Leyes de la versificación castellana. 2a edición. La Paz, González y Medina, 1919.

El Tucumán del siglo XVI (bajo el gobietno de Juan Ramírez de Velasco). Prólogo de Juan B. Terán. Buenos Aires, Coni Hnos., 1914.

El Tucumán colonial (Documentos y mapas del Atchivo de Indias). Volumen 1. Introducción y notas de Ricardo Jaimes Freyre. Buenos Aires, Coni Hnos., 1915.

Historia del descubtimiento de Tucumán, seguida de investigaciones históricas. Buenos Aires, Coni Hnos., 1916.

Los sueños son vida. Anadiomena. Las víctimas. Buenos Aires, Sociedad Cooperativa, 1917.

Los conquistadores. Drama histórico. (La Paz), 1928.

De las obras que a continuación se indican hemos hallado tan sólo el título en estudios relativos a Jaimes Freyre, sin haber encontrado hasta ahora más detalles:

Aspectos del Brasil. (Véase R. Villalobos, Letras bolivianas, La Paz, 1936, pp. 51-53.)

Historia de la Edad Media y de los tiempos modernos. (Véase W. B. Parker, Bolivians of To-day. New York, 1922, 2nd. ed., pp. 153-54.)

Histotia del Norte argentino. (Véase idem.)

El taller de Eufranor. (Véase J. B. Terán, Nosotros, Buenos Aires, abril 1933.)

Trovadotes y ttoveros. (Véase la obra de W. B. Parker antes citada.)

Entre otras, colaboró en las siguientes revistas: Anales de la Universidad de Tucumán, Revista de Amética, Revista de Lettas y Ciencias Sociales (Tucumán) y Revista Nacional de Literatura y Ciencias Sociales (Buenos Aires).

Vemos, pues, que sus dos libros de poesías fueron publicados con gran intervalo de tiempo: Castalia bárbara en 1899, Los sueños son vida en 1917. Su teoría de la versificación, publicada primero en dos artículos de revista en 1906, apareció en forma de libro en 1912. 
Jaimes Freyre fué el sólo poeta hispanoamericano de su escuela que se preocupó de fijar de manera científica su doctrina sobre la forma poética, lo que nos permite ver en él un artista reflexivo y consciente, y aumenta el valor de su significación en el movimiento modernista. ${ }^{1}$

Su pensamiento acerca de la forma del verso en castellano puede sintetizarse en sus propias palabras:

Los versos castellanos - dice en Leyes de la versificación castellana, $2^{\text {a }}$ ed., pp. 29 y 30 - se forman combinando períodos prosódicos.

Doy el nombre de período prosódico a una sílaba acentuada o a un grupo de sílabas no mayor de siete, de las cuales la última tiene acento intenso, estén o no acentuadas las otras.

Períodos prosódicos iguales son los que constan del mismo número de sílabas; análogos los que constan de un número desigual, pero sólo pares o sólo impares; diferentes los que constan de un número desigual, pares unos, impares los otros.

La combinación de períodos iguales o de períodos análogos, constituye el verso.

La combinación de periodos diferentes constituye la prosa.

Las estrofas o estancias se forman únicamente combinando versos que consten de períodos iguales o análogos entre sí; esto es, un verso formado por períodos pares no puede combinarse con otro formado por períodos impares.

Las breves líneas anteriores dejan percibir la flexibilidad de combinaciones que tal doctrina permite al poeta por encima de las posibilidades ofrecidas por las formas tradicionales; pero también que Jaimes Freyre exige del poeta un esquema de formas de las que el escritor no debe apartarse si quiere producir versos.

Este cuerpo de doctrina de la versificación, que no deja de tener sus puntos débiles como demuestra G. Dundas Craig en la obra mencionada en la bibliografía, debía ya de tenerla formulada Jaimes Freyre en 1899, por lo menos en sus elementos esenciales, por cuanto a ella se atienen las combinaciones que emplea en Castalia bárbara.

La lectura de dicho libro de versos confirma el hecho de que Jaimes Freyre era un escritor que trataba de realizar una obra trabajada, pensada, de forma cuidadosa. Las poesías contenidas en ese volumen, hermosas en su expresión, en sus figuras, en sus motivos, son, como el título de la obra lo indica, producto de una musa bárbara. La influencia del gran poeta de la lengua en aquella hora, Rubén 
Darío, no se halla presente en los poemas de Castalia bárbara más que en el esfuerzo de liberación temática y formal que el libro representa, pero el tono de $A z u l .$. y de Prosas profanas no es el del Jaimes Freyre de 1899; tampoco el Lugones de Las montañas del oro parece asomar en esas poesías (salvo acaso un reflejo del reflejo de Edgar Allan Poe); los precursores del modernismo hispánico no han dejado en nuestro escritor más que el tono general de melancolía. Así pues, esos poemas de leyenda nórdica, de saga escandinava, empapados de las brumas de la última Thule, ¿dónde encuentran su origen? El maestro del modernismo, el Darío de fines de siglo, está todavía lleno de exotismo francés y helénico; ¿a adónde ha ido Ricardo Jaimes Freyre a buscar inspiración en su deseo de novedad y de evasión?

Una inspección de la poesía francesa del siglo XIx nos ofrece respuesta inmediata. Jaimes Freyre, temperamento científico, teórico de la forma, creador de una doctrina del verso castellano, había de ver un maestro conforme a su espíritu en Leconte de Lisle, renovador también en Francia, gran burilador de sus versos, traductor de los clásicos, escritor de temas exóticos, teorizante del objetivismo poético. El conocimiento general de la poesía francesa en Hispanoamérica, la importancia poética de Charles Leconte de Lisle y la posición doctrinal de Ricardo Jaimes Freyre, permiten estimar que no hace falta una confesión de parte para dejar sentado este punto de historia literaria.

Castalia bárbara titula Jaimes Freyre su primer libro de versos; Poèmes barbares (1862) había llamado a una colección de los suyos Leconte de Lisle. "La muerte del héroe", "Los Elfos", "La espada", "El Walhalla", "Los Cuervos", son poemas del boliviano que pudieron hallar inspiración en trozos de algunos poemas bárbaros de Leconte. Y más aún que poemas determinados, el tono poético general de Castalia bárbara está en los Poèmes barbares. Hemos usado antes la palabra "inspiración", porque Ricardo Jaimes Freyre era demasiado poeta, estaba demasiado en posesión de sus medios artísticos, para que necesitase nada más.

Para ilustrar tal sugestión, compárense los siguientes versos:

Tous sont muets. Mon casque est tompu, mon atmute

Est trouée, et la hache a fait sauter ses clous.

Mes yeux saignent. J'entends un immense murmute

Pateil aux hutlements de la mer ou des loups. 
Viens par ici, Corbeat, mon brave mangeur d'hommes

A tite d'aile vole, ô todeut de btuyète!

Je vaix m'asseoit parmi les Dieux, dans le soleil!

de Poèmes barbares, titulados "Le coeur de Hialmar", con los siguientes de "La muerte del héroe" que se hallan en Castalia bárbara:
Aún se estremece y se yergue y amenaza con su espada, cubre el pecho destrozado su rojo y mellado escudo, hunde en la sombra infinita su mirada y en sus labios expirantes cesa el canto heroico y rudo.
Los dos Cuervos silenciosos ven de lejos su agonía $y$ al guerrero las sombrías alas tienden,
y la noche de sus alas, a los ojos del guerrero, resplandece como el día y hacia el pálido horizonte reposado vuelo emprenden.

En ambas poesías hay la misma expresión de silencio físico (tous sont muets - cesa el canto heroico y rudo), del estado de las armaduras (mon casque est rompu, mon armure est trouée - cubre el pecho destrozado su rojo y mellado escudo), el mismo animal amistoso y fatídico (viens par ici, Corbeau - los dos Cuervos silenciosos), el mismo vuelo armonioso (à tire d'aile vole - reposado vuelo), la misma impresión luminosa en los ojos del guerrero moribundo (dans le soleil - resplandece como el día).

Consciente $o$ inconscientemente, existe en el poeta joven un tono mimético respecto del escritor consagrado. No parece imitación, pero sí unidad de tono, producto del mismo estado de espíritu; y esta impresión aumenta al leer y releer los poemas de uno y otro escritor, por ejemplo "Les Elfes", de Leconte, y "Los Elfos", de Jaimes Freyre, aunque el del boliviano es superior al del francés. Hasta el mismo famoso poema "Aeternum vale", de Jaimes Freyre, la victoria de Cristo sobre los dioses de la mitología nórdica, pudiera hallar un antecedente, en ambiente distinto, en la victoria de Cristo sobre el mahometismo de "La fille de l'Emyr", de Leconte.

En el grupo de poesías publicadas en Los sueños son vida, dieciócho años más tarde, el tono poético es sensiblemente distinto del de Castalia bárbara. La influencia de Rubén Darío es mucho mayor, 
el sol de Grecia, de Francia, de España, rompe las brumas septentrionales de la obra primera. El parnasianismo estricto de Castalia bárbara cede en Los sueños son vida a una fusión de la brillantez formal con la significación simbolista.

En efecto, las poesías de Castalia bárbara, con toda su belleza de forma, en su mayoría carecen de contenido y de significación que nos conmuevan inmediatamente; en cambio, las poesías de Los sueños son vida son más humanas, menos frías, menos objetivas, ménos estatuarias quizá, pero más vivas. Compárese, por ejemplo, "El canto del mal" de la primera obra, con "Al borde de la tumba de Tolstoi", de la segunda.

E1 Jaimes Freyre de Castalia bárbara hubiera podido suscribir las palabras de Leconte de Lisle en su prólogo a Poèmes antiques (1852):

Ce livre est un recueil d'études... Les émotions petsonnelles n'y ont laissé que peu de traces; les passions et leṣ faits contémpotains n'y appataissent point.

Le thème personnel et ses variations répétées ont épuisé l'attention; l'indiffétence s'en est ensuivie à juste titre; mais s'il est indispensable d'abandonner au plus vite cette voie étroite et banale, encore ne faut-il s'engager en un chemin plus difficile et dangeteux, que fortifié pat l'étude et l'initiation. Ces épreuves expiatoites une fois subies, la langue poétique une fois assainie, les spéculations de l'esprit, les émotions de l'âme, les passions du coeut, petdront-elles de leut vétité et de leut énetgie, quand elles disposeront de formes plus nettes et plus précises... Et plus tard... dans un siècle ou deux. peut-être la poesie tedevienttat-elle le verbe inspité et immediat de l'âme humaine.

Afortunadamente, Ricardo Jaimes Freyre abrevió el plazo que Leconte de Lisle pensaba necesario para una purificación de la materia poética, y en la obra publicada en 1917 supo aunar la belleza formal con una expresión más subjetiva.

El simbolismo, producto en parte de influencias clásicas, inglesas y alemanas en las letras de Francia, de Wagner y su música, de Hegel y su filosofía, y los medios que ponían en manos del artista la encarnación de ideas en los personajes, el empleo de la alegoría, de la alusión, del valor musical del verso, estaban demasiado en el ambiente poético de la época para que un hombre de la sensibilidad artística de Jaimes Freyre pasase a su lado sin aprovecharse de ellos. 
Sin embargo, aun con estas adquisiciones simbolistas, la esencia de la poesía publicada en Los sueños son vida sigue siendo parnasiana; quizás protegido el escritor por aquella su "fría y segura serenidad" de que nos habla Díez de Medina, conservó mucho más que los demás modernistas la objetividad y el tono impersonal, esencialmente parnasianos, y que figuran hasta en sus poemas de amor:

\section{Lluvia de azahares} sobre un rostro níveo.

Las características esenciales del modernismo: trabajo consciente del estilo como reacción contra el desaliño romántico, perfeccionismo estético como reacción contra el lugar común ochocentista, exotismo como reacción contra el medio ambiente americano, cosmopolitismo cultural por mimetismo de las naciones líderes en el campo del avance económico y cultural de la época, todas se hallan en la obra de Ricardo Jaimes Freyre.

Dice Rubén Darío en Los raros (4a ed., Maucci, p. 41), refiriéndose al creador del parnasianismo francés: "La fama no ha sido propicia a Leconte de Lisle. Hay en él mucho de olimpico, y esto le aleja de la gloria común de los poetas humanos." Las mismas palabras pudieran aplicarse a Ricardo Jaimes Freyre; los escritores jóvenes de América han olvidado al poeta boliviano; los más jóvenes, y los mejores, hombres de la América poética, han abandonado los climpos, y atendiendo a las voces de la tierra, se baten hoy en las trincheras de la humanidad.

\section{Luis Monguió, Mills College.}

\section{NOTA}

1 También Manuel González Prada - a quien debe considerarse como uno de los precursores del modernismo- se preocupó de fijar, de manera científica, su doctrina sobre la forma poética, que presenta en las notas por él escritas para su edición de Exóticas (1911), y que en parte había seguido en Minúsculas (1901) y siguió en libros posteriores. Las doctrinas de González Prada y de Jaimes Freyre — que son bastante empíricas, aunque muy interesantes- se asemejan mucho. Véase Antología poética, de González Prada (Introducción y Notas). Bibl. de CLÁsICOS DE AMÉRICA, vol. 1, Ediciones del Instituto Internacional de Literatura Iberoamericana, México, 1940. 


\section{TRABAJOS CONSULTADOS}

Alarcón, Abel.—"La literatura boliviana", 1545-1916. Revue Hispanique, XLI, 1917, pp. 563-633.

Axel Charles. - Dans les montagnes, de Ricardo Jaimes Freyre. Traduction française por Charles Axel. Revue de l'Amérique Latine, Paris, XVI, 1928, pp. 523-528.

Barreda, Ernesto Mario.-_"Ricardo Jaimes Freyre: Un maestro del simbolismo." Nosotros, Buenos Aires, XXVII, 1933, pp. 285-290.

Blanco-Fombona, Rufino.-El modernismo y los poetas modernistas. Madrid, 1929, pp. 341-343.

Bulletin of the Pan-Ametican Union.-Washington, D. C., LVII, 1933, pp. 547-549: "The new Minister of Bolivia." (Con una fotografía.)

Carrasco, Aliro.-Letras Hispanoamericanas. Santiago de Chile, 1919, p. 153.

Coester, Alfred.-An Anthology of the Modernist Movement in Spanish America. Boston, 1924, pp. 137-141 y 290-292.

Cortés, José Domingo,-Patnaso botiviano. Valparaíso, 1869, pp. 167-174.

Cortés, José Domingo.-Patnaso peruano. Valparaíso, 1871, pp. 231-245.

Craig, G. Dundas.-The Modernist Trend in Spanish American Poetry. Berkeley, California, 1934, pp. 4, 12, 13, 16-17, 88-95, 281-286, 286-289.

Darío, Rubén.-Autobiografía. Editorial Mundo Latino, Obras completas, volumen XV, Madrid, 1918, pp. 147-148.

Dario, Rubén.-Los ratos. Editorial Maucci, 4a edición, Barcelona, s. a., p. 41.

Díez de Medina, Fernando.- "Los hombres como símbolos: Ricardo Jaimes Freyre." Repertotio Americano, San José de Costa Rica, XV, núm. 646, 12 de agosto de 1933, pp. 88-92.

Dirección General de Estadística y Estudios Geográficos de Bolivia--Hombes célebres de Bolivia. De siglo a siglo. La Paz, 1920, pp. 353-355.

Guerra, José Eduardo.-Poetas contemporáneos de Bolivia. La Paz, 1920, pp. $79,96,97,143$.

Leavitt, Sturgis E.-A Tentative Bibliography of Bolivian Literature. Cambridge, Mass., 1933.

Lugones, Leopoldo.--Prólogo a Castalia bátbara de Ricardo Jaimes Freyre. Buenos Aires, 1899 (Ed. Cultura, 1920).

Melián Lafinur, Alvaro.- "Leyes de la versificación castellana de Ricardo Jaimes Freyre." Nosottos, Buenos Aires, VII, 1913.

Nación, La.-Buenos Aires. "Ricardo Jaimes Freyre. Falleció ayer." Número del martes 25 de abril de 1933. (LXIV, núm. 22, 161), p. 7.

Nación, La.-Buenos Aires. Número del miércoles 26 de abril de 1933, p. 8.

Nación, La.-Buenos Aires. Número del jueves 27 de abril de 1933, p. 10.

Onís, Federico de.-Antología de la poesía española e hispanoameticana (18821932). Madrid, 1934, pp. 365-369 y apéndice. 
Parker, William B.-Bolivians of To-day. 2d. edition. New York, 1922, pp. $151-153,153-154$.

René Moreno, Gabriel.- "Primer suplemento a la Biblioteca Boliviana de Gabriel René Moreno" (1879-1899). Santiago de Chile, 1900.

Terán, Juan B.- "Ricardo Jaimes Freyre." Nosotros, Buenos Aires, XXVII, 1933, pp. 280-284. (Con una fotografía.) Reimpreso en Repertotio Americano, San José de Costa Rica, de 12 de agosto de 1933.

Torres-Rioseco, Arturo.-Rubén Datio. Americanismo y casticismo. Cambridge, Mass., 1931, p. 47.

Torres-Rioseco, Arturo.- "Ricardo Jaimes Freyre." Hispania (California), XVI, 1933, pp. 289-298.

Torres-Rioseco, Arturo.-The Epic of Latin American Literature. New York, 1942, pp. 99-100.

Villalobos, Rosendo.-Letras bolivianas. Los poetas y sus obras. Los prosistas literarios. La Paz, 1936, pp. 43-46, 51-53, 131. 
